\section{Tobacco exceptionalism in airports: time to address gaps}

\author{
Ruth E Malone
}

As I write this, I am preparing for a trip by air to attend a meeting. It is not a long flight, but the flight experience will be very different than it would have been years ago. Yes, passengers have to go through much more intensive screening before boarding the aircraft. Meals are no longer being served on short-haul flights as they once were; instead, we are offered overpriced salt-filled, sugar-filled and fatfilled 'snack boxes'. Every seat on the plane will probably be filled, and the overhead bins stuffed to the gills. However, those less pleasant changes for me are more than offset by a change for the better: smoke-free flights.

It is hard to imagine now, but not so long ago, it was considered completely normal to smoke cigarettes on airplanes. Enclosed in a sealed metal shell, passengers fastened their seat belts and awaited take-off. Once the plane was airborne, the overhead no smoking sign flicked off and clouds of toxic cigarette smoke would immediately waft from the 'smoking section', an area of seats usually located at the back of the main cabin but completely unseparated from others. Sometimes people even lit up cigars. Flight attendants brought meals and drinks and assisted passengers, working in a blue haze that often left them raw-throated and smelling like ashtrays by the end of a long day of flying. But worse than that, it also left them occupationally exposed to a major risk factor for multiple diseases.

Correspondence to Professor Ruth E Malone, Department of Social and Behavioral Sciences, School of Nursing, University of California, San Francisco, CA 94118, USA; ruth.malone@ucsf.edu
It has been 25 years since a courageous group of flight attendants concerned about their health fought for protection through their union until the USA finally banned smoking on domestic flights; many other countries followed, and eventually smoking was banned on almost all international flights as well. However, many non-smoking flight attendants suffered the disease consequences of years of occupational secondhand smoke exposure: some died from lung cancer; many developed chronic obstructive pulmonary disease or other ailments and continue to suffer even now, long after their retirement. Eventually, as part of a settlement, the Flight Attendant Medical Research Institute was created, which focuses on funding scientific research on diseases caused by exposure to tobacco smoke. ${ }^{1}$

So, the air in airplanes is better. However, the work of protecting all air transit workers and the public from this entirely preventable toxic exposure is not done. In this issue, two Brief Reports highlight continuing exposure to secondhand tobacco smoke in airports. Kungskulniti et $a l^{2}$ measured particulate matter using well-established procedures at Thai international airports and found levels to be higher than those of international airports in the USA. While smoking is prohibited in Thai domestic airports, 'designated smoking rooms' still exist in international terminals. As has now been demonstrated in multiple studies, partial smoking bans are ineffective in protecting the public and workers from secondhand smoke.

In a second article, Stillman et $a l^{3}$ review smoking policies of 34 major international airports around the world and report that over $50 \%$ of them still have smoking rooms or smoking areas, including some located in countries with otherwise strong national smoke-free policies. There are now over 600 US airports that are $100 \%$ smoke-free, and they seem to be doing fine. ${ }^{4}$ What is the mystery? Smoking rooms simply do not protect non-smokers or the workers who must clean and service them.

This is just another example of the strange, persistent 'exceptionalism' around tobacco that prevents implementation of effective public health protection. Just because a worker's job is at an airport (or a casino, or a hotel without $100 \%$ smokefree rules) does not mean he or she is immune to the effects of secondhand smoke. There is nothing so special and unique about an airport that requires it. This is a major policy gap and travellers should let airport managers know they want it addressed. It is past time.

Competing interests None declared.

Provenance and peer review Commissioned; internally peer reviewed.

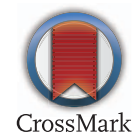

To cite Malone RE. Tob Control 2015;24:527.

Tob Control 2015;24:527.

doi:10.1136/tobaccocontrol-2015-052723

\section{REFERENCES}

1 Flight Attendant Medical Research Institute. History. http://wwwfamriorg/about_famri/historyhtml

2 Kungskulniti N, Charoenca N, Peesing J, et al. Assessment of secondhand smoke in international airports in Thailand, 2013. Tob Control 2015;24: 528-31.

3 Stillman F, Soong A, Kleb C, et al. A review of smoking policies in airports around the world. Tob Control 2015;24:524-7.

4 American Nonsmokers' Rights Foundation. 100\% smokefree U.S. airports. 2015. http:// wwwno-smokeorg/pdf/100smokefreeairportspdf 